\title{
Cultural Heritage and Natural Hazard: How WRF Model Can Help to Protect and Safe Archaeological Sites
}

\author{
G. Castorina ${ }^{1}$, F. Colombo ${ }^{1,2}$, M.T. Caccamo ${ }^{1}$, A. Cannuli ${ }^{1}$, V. Insinga ${ }^{3}$, E. Maiorana ${ }^{3}$, \\ S. Magazù ${ }^{1 *}$ \\ ${ }^{I}$ Department of Mathematical and Informatics Sciences, Physical Sciences and Earth Sciences (MIFT), \\ University of Messina, Viale F. S. D'Alcontres 31, 98166 Messina, Italy \\ ${ }^{2}$ Italian Air Force Meteorological Service - Comando Aeroporto - Sigonella, Catania, Italy \\ ${ }^{3}$ Consorzio Interuniversitario Scienze Fisiche Applicate (CISFA),Viale F. S. D'Alcontres 31, 98166 Messina, \\ Italy
}

*Corresponding Author: S. Magazù, Department of Mathematical and Informatics Sciences, Physical Sciences and Earth Sciences (MIFT), University of Messina, Viale F. S. D'Alcontres 31, 98166 Messina, Italy.Email: smagazu@unime.it

\begin{abstract}
Italy is an extraordinary outdoor museum thanks to its 51 UNESCO sites, more than 200.000 architectural monumental and archaeological assets, 3.400 museums and about 200.000 archaeological sites and areas. Although this country is considered a world leader in terms of humanity cultural heritage, it is particularly exposed to landslides, floods, earthquakes, subsidence, coastal erosion and volcanic eruptions. With the exception of earthquakes and volcanic eruptions, the remaining phenomena have often as trigger an extreme meteorological event, capable of producing large amounts of precipitation and consequently significant environmental damages. In this paper it will be shown how a spatial and temporal high-resolution meteorological model, optimized for Sicily, one of the richest regions in terms of cultural heritage, provides useful evaluation elements that can facilitate the management and safety of archaeological sites and cultural assets.
\end{abstract}

Keywords: WRF model, cultural heritage, heavy rain,extreme meteorological events

\section{INTRODUCTION}

Over the last 30 years, the theme of climatic changes has become one of the most widely discussed topics by the media from all over the world as well as by the international scientific community. This multidisciplinary phenomenon has been widely debated and discussed by Physics, Mathematicians, Meteorologists, Climatologists, Geologists, Archaeologists, etc.... One of the most interesting aspects of the phenomenon is the comprehension of the relationship between the increase of global temperatures and the increase of violent phenomena. The Mediterranean area and Sicily represent, from this point of view, an important "Hot Spot" and a natural laboratory, in which it is possible to study the effects of this climatic change. Several works have established a connection between global change and the increasing frequency of extreme events(Chen and Lin, 2005; Chen and Sun, 2002). In the case of Sicily, the Ionian coast represents an area of considerable interest from the weatherclimate point of view, because of its morphological conformation, characterized by a complex orography and by the proximity of the Ionian sea, capable of producing huge volumes of humid-hot air masses(Clyne et al., 2007). One of the most interesting fields of study is connected with the improvement of the performances and with the optimization of meteorological models when the climatic conditions change and to adapt them, as precisely as possible, to the territory of the forecast area. In this perspective, in a recent work(Caccamo et al. 2017) the improvements obtained by the model WRF, improving the geographic data DEM and the soil-use data are reported(Davolio et al., 2009; Miglietta and Rotunno, 2009). These extreme meteorological events have significant repercussions on daily life, not only for damage to buildings, agriculture and, in the most tragic circumstances, loss of human lives but also relevant negative consequences for the historical and cultural heritage(Cassar,2005; Adger et a. 2013; Aplin, 2007, Hutchings and Cassar, 2006; Wilby, 

Sites

2007).A recent study carried out by "Istituto Superiore per la Protezione e la Ricerca Ambientale (ISPRA) reveals that more than 40.0000 of cultural assets (museums, archaeological sites, churches and historic buildings) are at risk of flood; more than 38.000 are at risk of landslides, of which almost 11.000 in high and very high hazard classes. Therefore, it clearly emerges how is important the phase of prevention of these phenomena.

For this purpose, an experiment was carried out on the reconstruction of the alluvial event of 25 November 2016, which has invested the entire territory of Sicily, and in particular the area of Giardini Naxos, in which the Naxos Archaeological Park falls.

In the following a description of the model and its operating principles is given; then the case study is described and, finally, the conclusions are drawn.

\section{WRF MODEL}

The Weather Research and Forecasting (WRF) model is a new generation system of numerical forecast designed for operational forecasting of atmospheric phenomena.

The WRF is the result of collaboration between the National Centre for Atmospheric Research (NCAR), the National Centre for Environmental Prediction (NCEP) and the Earth's System Research Laboratory (ESRL) of the National Oceanic and Atmospheric Administration (NOAA).

The structure of the model consists of a central nucleus, called the WRF Software Framework (WSF), which is formed of several assimilation and parameterization schemes of the physicochemical variables to which pre and post processing modules are connected.

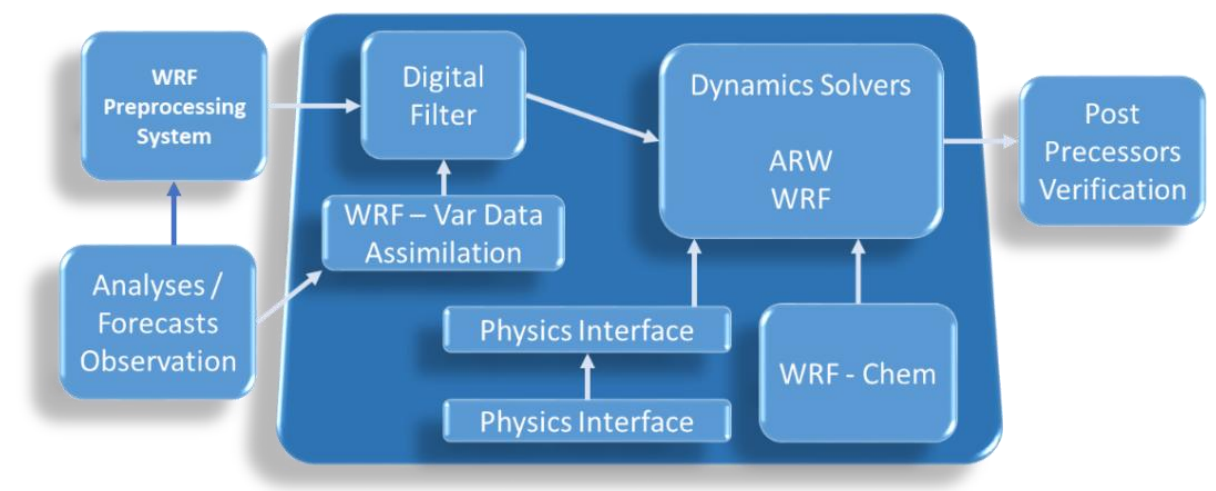

Fig. 1: Block diagram of WRF Software Framework (WSF)

The pre-processing phase (WPS) includes 3 calculation routines, Geogrid, Ungrib, and Metgrid that sequentially take care to elaborate the data that drive the model. Geogrid creates static data that includes geographic data and soil use data; Ungrib assimilates the GRIB data collected by the global computing centers, while Metgrid intercepts the horizontal weather data, scaling them to the domain originally defined.

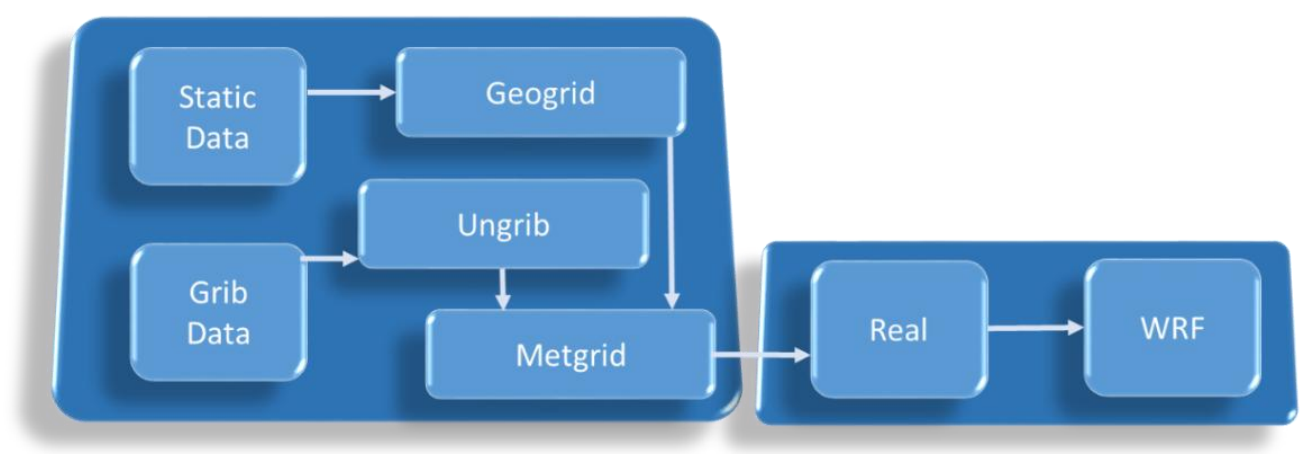

Fig. 2: Block diagram of Pre-processing System (left) and Real Data ARW System (right)

The pre-processed data are passed to other routines, in this case the WRF-REAL that interpolates the data in the spatial coordinates of the model.

The final step of process regards the production of output data and graphic post processing.

The WRF has two dynamical cores: 

Sites

- the Advanced Research WRF (ARW), supported and developed by National Center of Atmospheric Research (NCAR), able to simulate different typologies of meteorological events with different spatial resolutions.

- the Non-hydrostatic Mesoscale Model (NMM), developed by National Center for Environmental Prediction (NCEP), able to work both in hydrostatic and in non-hydrostatic way.

The model WRF results to be very versatile and it allows the use different typologies of parameterizations as it regards, for instance, the microphysics of the clouds, the convection, the turbulent flows inside the Planetary Boundary Layer, the radiative and diffusive processes.

\section{A local area model for Sicily: the WRF-UNIME}

A limited area model WRF with core ARW version 3.9 has been installed and optimized for purposes of operational research.The model configuration is optimized for Sicily. The improvement concern the increase of the spatial resolution of the geographical data (ASTER GDEM V2 with 30m of horizontal resolution), the optimization of the local parameters of use of the soil and vegetative coverage (CORINE CLC with $100 \mathrm{~m}$ of horizontal resolution) and the acquisition of the high definition sea surface temperature (SST) data (RTG SST HR with $0.083^{\circ}$ of resolution)(De Meiji and Vinuesa, 2006).The configuration of the physics parameterization is show in the follows table:

Tab. 1: Parameterization used for the WRF model optimized for Sicily.

\begin{tabular}{|l|l|}
\hline CU parameterization & Betts-Miller-Janjic - Explicit \\
\hline Microphysics parameterization & Thompson \\
\hline Shortwave radiation option & RRTMG \\
\hline Longwave radiation option & RRTMG \\
\hline Surface layer option & Eta Similarity Scheme \\
\hline Land surface option & Unified Noah Land Surface Model \\
\hline Planetary Boundary Layer scheme & Mellor-Yamada-Janjic MYJ \\
\hline
\end{tabular}

The WRF-UNIME model is configured to run with different resolution till $1.1 \mathrm{~km}$ of grid spacing. It run twice a day at 00 and 12 UTC. In table 2 are shown the characteristics of the different run in use at Messina University:

Tab. 2: Run and features of the WRF UNIME model.

\begin{tabular}{|l|l|l|l|l|l|}
\hline RUN & Grid spacing & Forecast time & Time step & Initialization data & Number of daily run \\
\hline ARW $10 \mathrm{~km}$ & $10 \mathrm{~km}$ & $120 \mathrm{~h}$ & $1 \mathrm{~h}$ & GFS $0.25^{\circ}$ & $2(00,12 \mathrm{z})$ \\
\hline ARW $3.3 \mathrm{~km}$ & $3.3 \mathrm{~km}$ & $72 \mathrm{~h}$ & $1 \mathrm{~h}$ & UNIME $10 \mathrm{KM}$ & $2(00,12 \mathrm{z})$ \\
\hline ARW $1.1 \mathrm{~km}$ & $1.1 \mathrm{~km}$ & $36 \mathrm{~h}$ & $1 \mathrm{~h}$ & UNIME $3 \mathrm{KM}$ & $2(00,12 \mathrm{z})$ \\
\hline
\end{tabular}

\section{Synoptic analysis and case study}

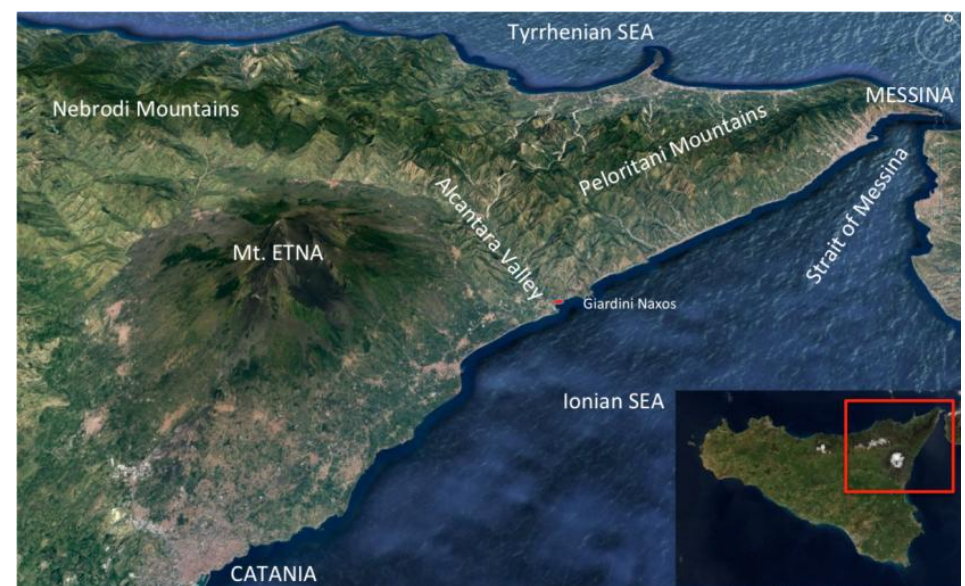

Fig.3 Geography of the analysed area.( taken from Caccamo et al. 2017)

The Eastern coast of Sicily, see fig. Fig.3, due to its morphological conformation, characterized by a complex orography, is very sensible to flash floods (Cassola et al., 2015). Particularly the thin strip that from Catania goes toward north up to Messina, it has suffered during the last decades an impressive sequence of disastrous events. 

Sites

In the area there are numerous archaeological sites and naturalistic and cultural goods revert: the Timpa of Acireale, the archaeological Park of Naxos, the Greek Theatre of Taormina, only to quote some of it. The last event in chronological order occurred on 2016 November 25, when a severe storm produced heavy precipitations that within few hours reached $150 \mathrm{~mm}$. Such mass of water, has submerged the whole inhabited centre of Giardini, included the archaeological area of Naxos. A WRF-Unime re-analysis has been performed, in order to understand if and how a preventive alarm would have been able to avoid or mitigate the destructive effects.

The synoptic situation showed by the upper chart of 00:00 UTC of 2016 November 25 was characterized by an upper low located over Iberian Peninsula. Southwesterly upper streams and cyclonic rotations of winds affected Sicily, as shown in Fig. 4.

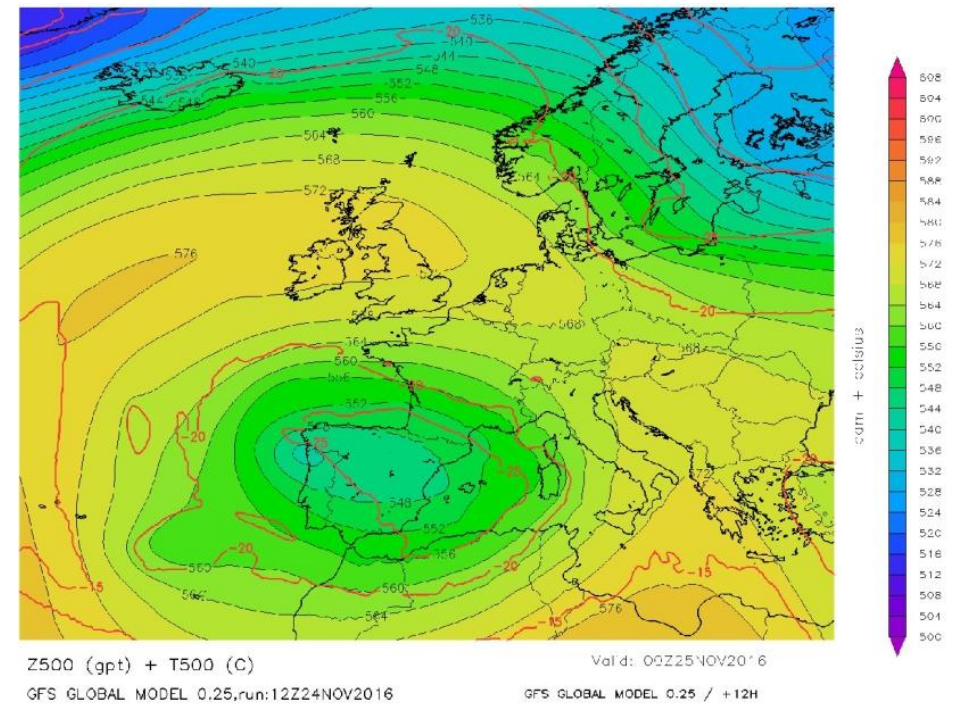

Fig. 4: Upper map at 500hPa of 25/11/2016, O0UTC

This situation was in line with the surface analysis, that showed a low pressure of $1000 \mathrm{hPa}$ in about the same position of the upper low. Over the western Mediterranean sea the pressure field was flat around values of $1012 \mathrm{hPa}$. In the hours right after 00:00 UTC, the first cold air impulses reaches the western coast of Sicily, initially causing spread thunderstorms in the Trapani area. The frontal lifting caused by the arrival of the cold air mass finds an environment ready to trigger a strong convective storm (Morrison and Milbrandt, 2011, Kain, 2004). The storm line originates a huge V-shaped storm that increases just north of the island of Pantelleria, affecting all the western Sicily with intense precipitation, but particularly concentrated in the southern coast between the towns of Ribera and Sciacca. The V-shaped structure is clearly visible in MSG images coloured with the enhancing techniques, as reported in Fig. 5.

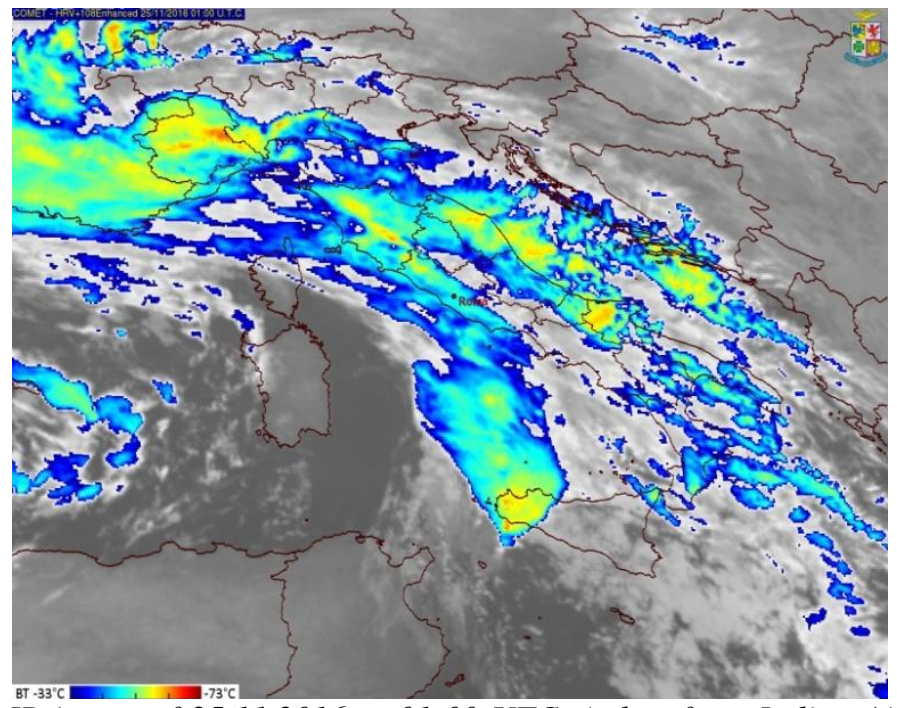

Fig. 5: Enhanced MSG IR image of 25.11.2016 at 01:00 UTC. (taken from Italian Air Force Meteorological Service) 

Sites

These "V" storm systems, better known as "V-Shaped", are powerful, mesoscale storm systems. In the southernmost part, close to the "V" tip, occurs the most intense precipitations and there may be formed some "supercellular" elements, holding intense rotation, which may generate swirling phenomena such as waterspout, not reported since not seen due to the night darkness.

Such an extreme event has been well forecast by WRF UNIME, optimized for the Sicilian territory, characterized by complex orography. The results are shown in Fig. 5, where the forecast obtained by WRF model 24 hours before the event, with the map of observed precipitation by Regional Department of Civil Protection are compared.

The forecast map, see Fig. 6, shows that the maxima rain accumulations were forecast in the southwestern area, with accumulation of about 60 to $120 \mathrm{~mm}$, as well in the north-eastern area where the accumulation forecast was more than $200 \mathrm{~mm}$. The visual comparison with the map of the precipitations accumulated of the Regional Department of Civil Protection shows the good accord between forecast and observation both as it regards the location of the event and the accumulation.

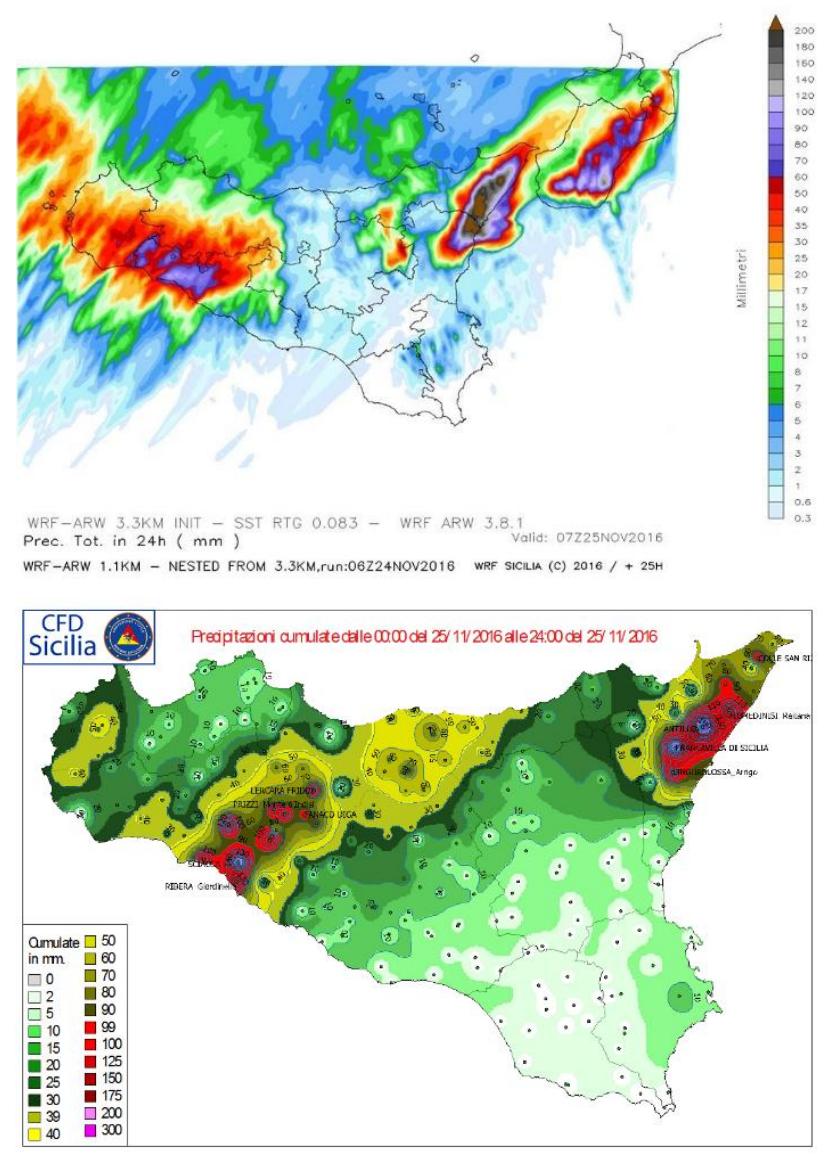

Fig. 6: Comparison between forecast precipitations obtained by WRF - UNIME model and observation data obtained by the regional meteorological stations network.(taken from DRPC - Sicily)

\section{CONCLUSiON}

The analysed case study clearly shows that the local area meteorological model WRF-UNIME, configured and optimized for the Sicilian territory, provides a good 24 hours forecast performance. The data forecast has been compared with the observations coming from the meteorological station regional network. The obtained agreement can be useful to make a plan useful for cultural heritage operators to get safe the cultural and historic sites. Furthermore, the WRF meteorological model can be fully coupled with a Chemical module. In this case, besides the meteorological forecast, the model could provide useful information regarding the emission, transportation, mixing and deposition of atmospheric pollutants which are often cause of damage for monument and archaeological sites. Thanks to the meteorologic forecast it is possible to give a support to different aspects of disaster risk management of cultural heritage. More precisely the meteorologic forecast allows to take into account 

Sites

the integrated risk assessment of cultural heritage, to create an integrated system for disaster risk management of cultural heritage which includes mitigation, adaptation, preparedness, response and recovery measures and to formulate appropriate urban and regional disaster management plans and policies.

\section{REFERENCES}

Adger WN, Barnett J, Brown K, Marshall N and O'Brien K. (2013). Cultural dimensions of climate change impacts and adaptation. Nature Clim. Change. (3):112-117.

Aplin, G (2007). World heritage cultural landscapes. Intern. J. Her. Studies. 13:427-446.

Hutchings $\mathbf{J}$ and Cassar J(2006). A soft system framework for the conservation management of material cultural heritage. System. Prac. Act. Res. (19): 201-216.

Caccamo MT, Castorina G, Colombo F, Insinga V, Maiorana E and Magazù S (2017).Weather forecast performances for complex orographic areas: Impact of different grid resolutions and of geographic data on heavy rainfall event simulations in Sicily, Atmos. Res. (198): 22-33.

Cassar, M (2005). Climate Change and the Historic Environment. London: University College London, Centre for Sustainable Heritage.

Cassola F, Ferrari F and Mazzino A (2015). Numerical simulations of Mediterranean heavy precipitation events with the WRF model: a verification exercise using different approaches. Atmos. Res. (164-165): 210-225.

Chen C, Lin Y, (2005). Orographic effects on a conditionally unstable flow over an idealized threedimensional mesoscale mountain. Meteorog. Atmos. Phys. (88): 1-21.

Chen SH, Sun WY (2002). A one dimensional time dependent cloud model. J. Meteorol. Soc. Jpn. (80):99-118.

Clyne J, Mininni P, Norton A and Rast M (2007). Interactive desktop analysis of high resolution simulations: application to turbulent plume dynamics and current sheet formation. New J. Phys. (9): 301-328.

Davolio S, Mastrangelo D, Miglietta MM, Drofa O, Buzzi A and Malguzzi P (2009). High resolution simulations of a flash flood near Venice. Nat. Hazards Earth Syst. Sci. (9): 1671-1678.

De Meiji A, Vinuesa J (2006). Impact of SRTM and Corine Land Cover data on meteorological parameters using WRF. Atmos. Res. (143): 351-370.

Kain JS (2004) The Kain-Fritsch convective parameterization: an update. J. Appl. Meteorol. (43): $170-181$.

Miglietta MM and Rotunno R (2009). Numerical simulations of low-CAPE flows over a mountain ridge. J. Atmos. Sci. (66): 2391-2401.

Morrison H and Milbrandt J (2011). Comparison of two-moment bulk microphysics schemes in idealized supercell thunderstorm simulations. Mon. Weather Rev. (139): 1103-1130.

Wilby R (2007). A review of climate change impacts on the built environment. Built Environ. (33): 31-45.

Citation: G. Castorina et al., "Cultural Heritage and Natural Hazard: How WRF Model Can Help to Protect and Safe Archaeological Sites ", International Journal of Research in Environmental Science , vol. 3, no. 3, p. 6, 2017. http://dx.doi.org/10.20431/2454-9444.0303004

Copyright: (C) 2017 Authors. This is an open-access article distributed under the terms of the Creative Commons Attribution License, which permits unrestricted use, distribution, and reproduction in any medium, provided the original author and source are credited. 